ORIGINAL ARTICLE

\title{
Systematic review of the dose-response relation of inhaled fluticasone propionate
}

\author{
M Masoli, M Weatherall, S Holt, R Beasley
}

Arch Dis Child 2004;89:902-907. doi: 10.1136/adc.2003.035709

See end of article for authors' affiliations .....................

Correspondence to: Professor R Beasley, Medical Research Institute of New Zealand, PO Box 10055, Wellington, New Zealand; richard.beasley@ mrinz.ac.nz

Accepted

17 November 2003
Aims: To examine the dose-response relation of inhaled fluticasone for both efficacy and adrenal function in children with asthma.

Methods: Systematic review of double blind randomised dose-response studies of fluticasone in children of at least 4 weeks duration. Main outcome measures: $\mathrm{FEV}_{1}$, morning peak expiratory flow, night awakenings, $\beta$ agonist use, major exacerbations, 12 or 24 hour urinary cortisol, peak plasma cortisol post-stimulation.

Results: Seven studies of 1733 children with asthma met the inclusion criteria for efficacy. The doseresponse curve for each efficacy outcome measure suggested that the response began to plateau between 100 and $200 \mu g$ per day with additional efficacy at the $400 \mu \mathrm{g}$ per day dose shown in one study of severe asthmatics. Five studies of 1096 children with asthma met the inclusion criteria for assessment of adrenal function. The largest placebo controlled study of 437 children reported no difference in 24 hour urinary cortisol between placebo and fluticasone at doses of 100 and $200 \mu \mathrm{g}$ per day. The non-placebo controlled study of 528 children reported significant suppression of overnight urinary cortisol levels with fluticasone at 400 compared with $200 \mu \mathrm{g}$ per day.

Conclusions: There is insufficient data to determine the dose-response of fluticasone in children at doses $>400 \mu \mathrm{g}$ per day. The dose-response curve for fluticasone appears to plateau between 100 and $200 \mu \mathrm{g}$ per day for efficacy. There was additional efficacy at the $400 \mu \mathrm{g}$ per day dose in children with severe asthma; however there was evidence of adrenal suppression at this dose.
1 $\mathrm{n}$ a recent meta-analysis of placebo controlled dose response studies of the inhaled corticosteroid fluticasone propionate we have shown that in adolescent and adult patients with asthma, most of the therapeutic benefit is achieved with a dose of between 100 and $250 \mu \mathrm{g}$ per day. ${ }^{1}$ The comparable dose-response relation for fluticasone in children with asthma has not been formally established for either efficacy or adverse systemic effects such as adrenal suppression. Recently there have been case reports of symptomatic adrenal insufficiency, ${ }^{2-5}$ including life threatening acute adrenal crisis ${ }^{6-9}$ attributed to fluticasone therapy at doses $\geqslant 500 \mu \mathrm{g}$ per day in children with asthma. This has prompted our group to undertake a systematic review of dose-response studies that have examined the efficacy and adrenal effects of fluticasone in children.

\section{METHODS}

\section{Search strategy}

We conducted a search of Medline from 1 January 1966 to June 2002 and of EMBASE from 1980 to June 2002 (see fig 1). On Medline we combined a search of studies containing the keyword "fluticasone" with a search using the MeSH subject heading "asthma" and "dose-response relationship", "drug" $(\mathrm{MeSH})$ or the keywords "dose" or "dosage", "children" or "childhood", and "adrenal" or "HPA axis". On EMBASE we searched for studies containing the keywords "fluticasone" and "dose" and "dosage". We asked GlaxoSmithKline, the manufacturer of fluticasone, for details of all relevant studies. We also examined the reference lists of relevant studies. Two people examined each paper's title and abstract and then the full paper if necessary.

\section{Inclusion criteria}

Placebo controlled studies

To be included in this meta-analysis, studies had to meet all the following criteria: a double blind randomised placebo controlled trial of children (4-16 years) with asthma; at least one dose of inhaled fluticasone; at least four weeks' duration.

For clinical efficacy, data on at least one of the following outcome measures was required, forced expiratory volume in one second $\left(\mathrm{FEV}_{1}\right)$ (litres), morning and evening peak expiratory flow ( $1 / \mathrm{min})$, use of $\beta$ agonists (puffs/day), night wakening, and withdrawal rate due to exacerbations of asthma.

For adrenal function, data were required on at least one sensitive measure of adrenal function including 12 or 24 hour urinary cortisol or plasma cortisol post-stimulation. Studies reporting single morning plasma cortisol measurements were excluded as this is a relatively insensitive and variable measure for detecting adrenal suppression. ${ }^{10-12}$

Non-placebo controlled studies

A secondary analysis was undertaken in which double blind randomised trials were studied that met the above criteria but studied at least two doses of fluticasone without the requirement to be placebo controlled. This secondary analysis was undertaken in an attempt to determine the doseresponse relation at doses $>200 \mu \mathrm{g}$ per day, which represented the highest dose studied with the placebo controlled studies.

\section{Data analysis}

Extraction of data was based on reported summary statistics (means, standard deviation, standard errors of means) for the intention to treat population. For each study the mean and standard deviation of the change from baseline was taken as the response variable with data taken from the text, tables, or estimated from figures. Standard methods for pooling continuous outcome variables were used. ${ }^{13}$ For study withdrawals, standard methods of pooling odds ratios were used. ${ }^{13}$ SAS version 8.2 and Minitab version 13.32 were used. 


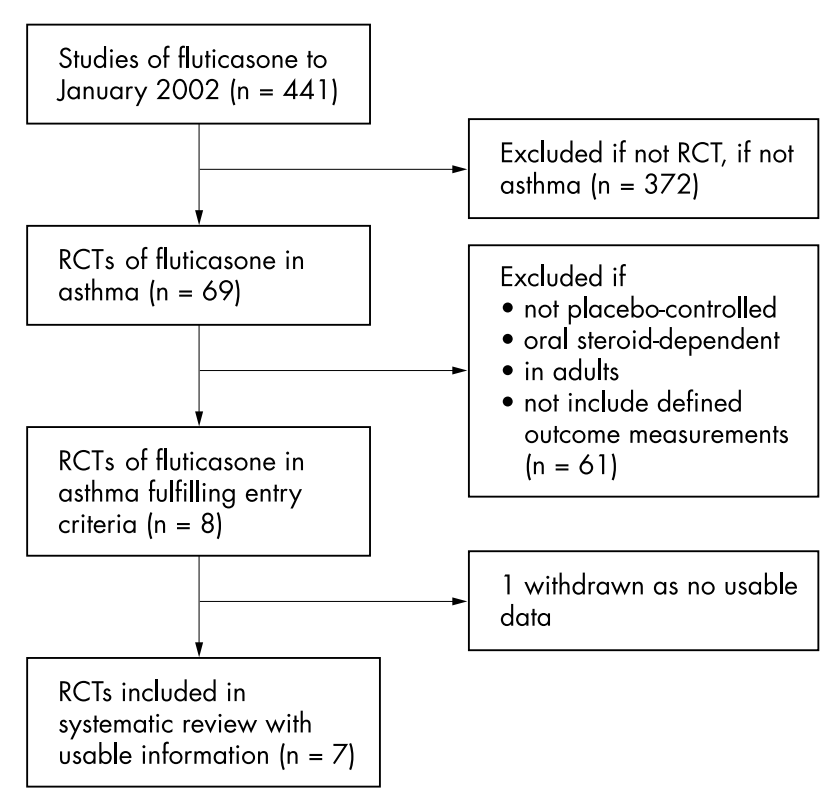

Figure 1 Process of inclusion of placebo controlled studies in the systematic review.

\section{RESULTS \\ Efficacy}

Placebo controlled studies

There were five studies with a total of 1150 children who met the inclusion criteria for the analysis of clinical efficacy (table 1). ${ }^{14-18}$ There were no studies in which doses $>200 \mu \mathrm{g}$ per day were examined. The study of Hofstra and colleagues, ${ }^{19}$ which examined doses of 200 and $500 \mu$ g per day was not included as it did not provide data in the required format; interpretation would also have been limited by both the small numbers and inclusion of children with baseline lung function close to predicted values.

A formal meta-analysis of the continuous outcome variables could not be performed as only one study ${ }^{15}$ reported means and a measure of variance for the continuous outcome variables for placebo, 100 and $200 \mu \mathrm{g}$ per day doses; in this study there was no statistically significant difference between the responses at 100 and $200 \mu \mathrm{g}$ per day. A plot of the raw data for each outcome measure against a dose of fluticasone suggested that the response begins to plateau between 100 to $200 \mu \mathrm{g}$ per day (fig 2). For continuous outcome variables the pooled response at $100 \mu \mathrm{g}$ per day was similar to the pooled response at $200 \mu \mathrm{g}$ per day (table 2 ).

All studies provided data regarding withdrawal and in all cases this was due to worsening asthma or respiratory symptoms. One study had a "zero cell count" for study withdrawal $^{16}$ and 0.5 was added to this cell to allow calculation of an odds ratio. For those two studies ${ }^{15} 17$ that directly compared 100 versus $200 \mu \mathrm{g}$ per day the odds ratio for the estimate of effect showed no significant difference between the two doses (table 3 ).

\section{Non-placebo controlled studies}

There were two studies with a total of 583 children who met the criteria for the analysis of clinical efficacy (table 1). ${ }^{20}{ }^{21}$ In the Verona and colleagues ${ }^{20}$ study of children with asthma previously requiring high dose inhaled corticosteroid therapy, fluticasone in a dose of $400 \mu \mathrm{g}$ per day resulted in a greater increase in clinic PEF than the $200 \mu \mathrm{g}$ per day dose, with a $17.8 \mathrm{l} / \mathrm{min}$ difference at the end of the 52 week study (table 4). The corresponding difference in morning and evening PEF as recorded in the daily record cards was 11.4 and $11.9 \mathrm{l} / \mathrm{min}$ respectively in favour of the higher dose regime; however there was no significant difference in exacerbation rates, which was the primary end point of the study.

In the Visser and colleagues ${ }^{21}$ study, children with asthma received fluticasone $200 \mu \mathrm{g}$ per day for 12 months or started with $1000 \mu \mathrm{g}$ per day with two monthly reductions to 500, 200, and $100 \mu \mathrm{g}$ per day, which was then maintained for six months. There was no difference in clinical outcomes including lung function, symptom scores, or exacerbations between the treatment schedules at any stage during the 12 month study period (table 4). As a result, there was no difference observed during the initial two month period with the 200 versus $1000 \mu \mathrm{g}$ per day comparison, or during the final six month period with 200 versus $100 \mu \mathrm{g}$ per day comparison.

\section{Adrenal function \\ Placebo controlled studies}

There were four studies with a total of 568 children who met the inclusion criteria for the analysis of the effects on adrenal function (table 5). ${ }^{15} 162223$ From these studies it was not possible to undertake a meta-analysis for effects on adrenal function due to differences in presentation of the data.

In the study of Peden and colleagues ${ }^{15}$ of 437 children, there was no difference in the 24 hour urinary cortisol between placebo and the 100 and $200 \mu \mathrm{g}$ per day doses of fluticasone delivered by either the diskhaler or diskus device. In the study of Hoekstra and colleagues ${ }^{16}$ of 34 children, morning urinary cortisol was significantly lower in the group taking fluticasone $200 \mu \mathrm{g}$ per day compared to placebo after three months of treatment. In both these studies, the number of children with abnormal adrenal function before and after treatment with the different regimes was not reported. In the study of Price and colleagues, ${ }^{22}$ there was no significant difference between the effect of fluticasone $100 \mu \mathrm{g}$ per day and sodium cromoglycate (placebo) in 24 hour urinary cortisol. However, four of the 52 children taking fluticasone were below the designated lower level of the normal range ( $50 \mathrm{nmol} / 24$ hours) after 12 months of treatment, with no abnormally low values observed in the placebo group. Kannisto and colleagues ${ }^{23}$ reported that $20 \%$ (6/30) of previously steroid naïve children had an abnormal response to low dose ACTH stimulation after two months of treatment with fluticasone $500 \mu \mathrm{g}$ per day. A similar proportion of children (5/30) had an abnormal response despite a reduction in the fluticasone dose to $200 \mu \mathrm{g}$ per day for a further two months. In contrast, children in the cromoglycate (placebo) group expressed a normal response to low dose ACTH stimulation throughout the study, including those children changed to cromoglycate after four months of fluticasone treatment.

\section{Non-placebo controlled studies}

There was one study of 528 children which met the inclusion criteria for the effects of adrenal function (table 5). ${ }^{20}$ In this study, the urinary cortisol concentrations for 400 versus 200 $\mu \mathrm{g}$ per day regimes were significantly different, with treatment ratios of 0.86 and 0.81 at weeks 16 and 52 respectively. In the total population, urinary cortisol levels remained unchanged or within the normal range in $91 \%$ and $95 \%$ of children taking 400 and $200 \mu \mathrm{g}$ per day respectively. Urinary cortisol concentration fell below the lower level of the normal range $(<5 \mathrm{nmol} / \mathrm{l})$ in nine children $(4 \%)$ in the fluticasone $400 \mu \mathrm{g}$ per day group, and in one child $(0.5 \%)$ in the $200 \mu \mathrm{g}$ per day group. 


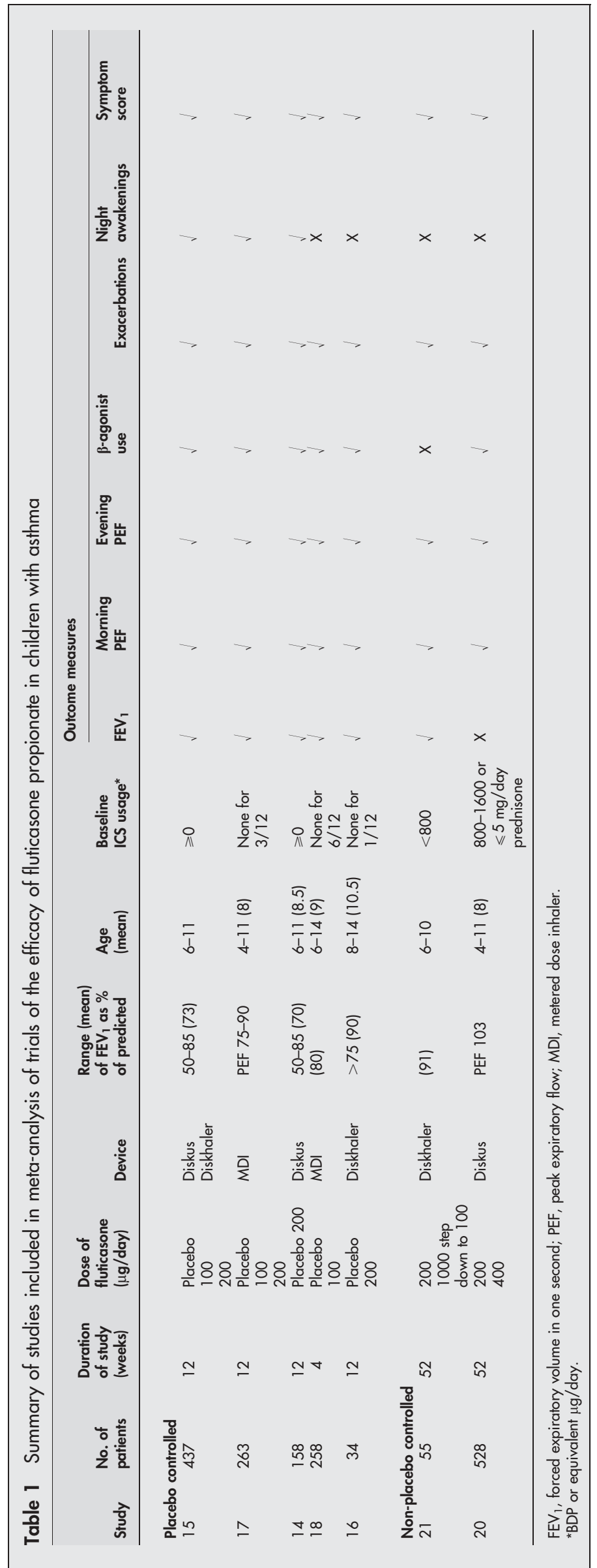


Table 2 Standardised differences (number of standard deviations) in change from baseline (95\% Cl) for continuous clinical outcome measures in placebo controlled studies

\begin{tabular}{lcc}
\hline & $100 \mu \mathrm{g}$ versus 0 * & $200 \mu \mathrm{g}$ versus $0 t$ \\
\hline $\mathrm{FEV}_{1}$ & $0.46(0.20$ to 0.72$)$ & $0.58(0.37$ to 0.78$)$ \\
$\mathrm{PEF}-\mathrm{am}$ & $0.58(0.32$ to 0.84$)$ & $0.64(0.45$ to 0.84$)$ \\
$\mathrm{PEF}-\mathrm{pm}$ & $0.49(0.23$ to 0.75$)$ & $0.60(0.40$ to 0.79$)$ \\
$\beta$ agonist use & $-0.48(-0.74$ to -0.22$)$ & $-0.44(-0.64$ to -0.23$)$ \\
Night wakenings & $-0.46(-0.73$ to -0.21$)$ & $-0.53(-0.73$ to -0.32$)$ \\
\hline *Derived from reference $15 ; 100 \mu \mathrm{g}$ minus $0 \mu \mathrm{g}$ per day. \\
†Derived from references $14-16 ; 200 \mu \mathrm{g}$ minus $0 \mu \mathrm{g}$ per day.
\end{tabular}

\section{DISCUSSION}

This systematic review has shown that for both efficacy and systemic effects the dose-response relation of fluticasone has been adequately examined in children only in doses of up to $400 \mu \mathrm{g}$ per day. In terms of efficacy, the dose-response curve appears to plateau between 100 and $200 \mu \mathrm{g}$ per day with further benefit achieved with the $400 \mu \mathrm{g}$ per day dose in children with severe asthma. However, at the $400 \mu \mathrm{g}$ per day dose of fluticasone there was evidence of adrenal suppression in a small but clinically significant number of children.

\section{Limitations}

The major limitations of this study are the small number of randomised placebo controlled studies which assessed the dose-response relation of fluticasone and that in these studies the highest dose examined for either efficacy or
Table 3 Pooled odds ratio for study withdrawal in placebo controlled studies (smaller odds ratio favours the higher dose)

\begin{tabular}{lll}
\hline $\begin{array}{l}\text { No. of } \\
\text { subjects }\end{array}$ & Comparison & Odds ratio $(95 \% \mathrm{Cl})$ \\
\hline 702 & 0 versus $100 \mu \mathrm{g}$ per day* & $0.26(0.16$ to 0.44$)$ \\
626 & 0 versus $200 \mu \mathrm{g}$ per day $\dagger$ & $0.20(0.13$ to 0.32$)$ \\
522 & 100 versus $200 \mu \mathrm{g}$ per day $\neq$ & $0.80(0.46$ to 1.37$)$ \\
\hline
\end{tabular}

*Derived from references 15,17 , and 20 .

†Derived from references 14-17.

fDerived from references 15 and 17 .

adrenal effects was $200 \mu \mathrm{g}$ per day. This led to a secondary analysis being undertaken, which involved non-placebo controlled dose-response studies, which enabled the clinical efficacy of doses $>200 \mu \mathrm{g}$ per day to be reviewed. However, despite this additional analysis, there was insufficient data to confidently determine the therapeutic index of fluticasone.

The major limitation in the assessment of adrenal function was that most studies made a single measurement of morning plasma cortisol which is recognised as an insensitive and variable measure of adrenal insufficiency. ${ }^{10-12}$ It is for this reason that we restricted our analysis to studies which had used assessment of either 12 or 24 hour urinary cortisol or post-stimulation serum cortisol responses, which are sensitive measures of adrenal function. ${ }^{1024-26}$ Another related problem was the standard reporting of mean changes in adrenal function without stating the proportion of children who developed an abnormal test following fluticasone
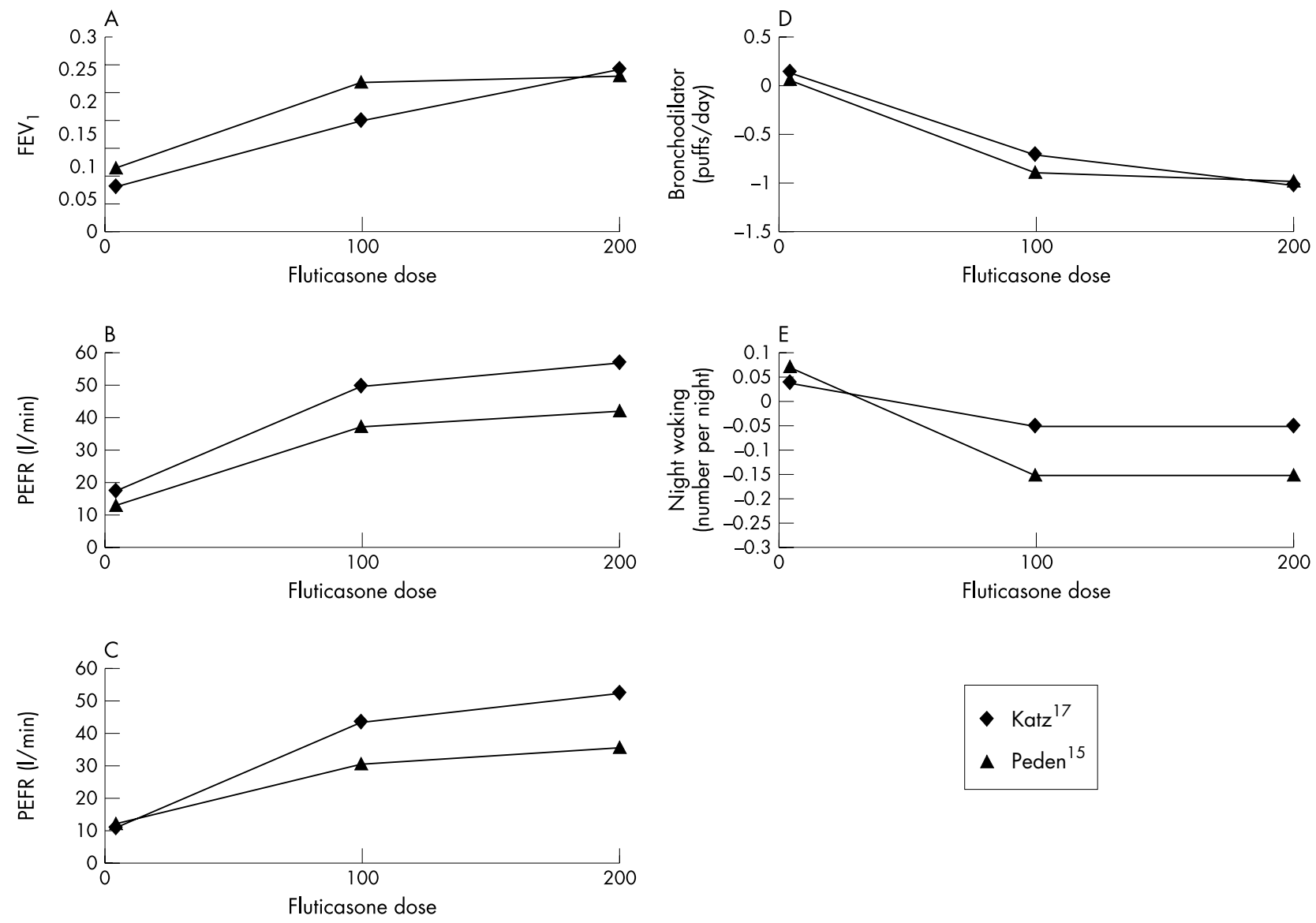

Figure 2 The change in outcome variable from baseline for $(A) F_{1},(B)$ morning PEF, (C) evening PEF, (D) bronchodilator use, (E) night wakening. Data are taken from Katz et al ${ }^{17}$ and Peden et al. ${ }^{15}$ 
Table 4 Mean difference in lung function measures in non-placebo controlled studies (positive number favours the $200 \mu \mathrm{g}$ dose)

\begin{tabular}{lccccc}
\hline & Weeks & FEV (I) & & PEF-am (I/min) & PEF- pm (I/min) \\
\hline $200 \vee 100 \mu \mathrm{g}^{*}$ & 26 & -3.0 & $(3.5)$ & $10.7(7.4)$ & $13.1(6.4)$ \\
$200 \vee 400 \mu \mathrm{g} \dagger$ & 52 & & & $-11.4(-5.6$ to -17.3$)$ & $-11.9(-6.2$ to -17.6$)$ \\
$200 \vee 1000 \mu \mathrm{g}^{*}$ & 8 & 3.6 & $(3.1)$ & $5.2(8.9)$ & $2.5(8.3)$ \\
\hline
\end{tabular}

*From reference 21; data expressed as mean (SE).

†From reference 20 ; data expressed as mean $(95 \% \mathrm{Cl})$.

treatment which would have been informative due to the marked individual variability in response that may occur. Another limitation was the lack of long term studies which is likely to have resulted in an underestimation of the magnitude of the effect due to the greater propensity to develop adrenal suppression with treatment beyond one year. ${ }^{24}$

\section{Efficacy}

For the different measures of efficacy the analyses from the placebo controlled studies indicated that the dose-response appeared to plateau between 100 and $200 \mu \mathrm{g}$ per day. It was possible to examine the effect of higher doses in the two nonplacebo controlled studies. In the 12 month study of children with severe asthma previously requiring high dose inhaled corticosteroids, there was a greater improvement in lung function with the $400 \mu \mathrm{g}$ per day of fluticasone compared with the $200 \mu \mathrm{g}$ per day dosage regime, but with no difference in exacerbation rates. ${ }^{20}$ In the smaller study of children with moderately severe asthma there was no difference in efficacy between fluticasone 200 versus $1000 \mu \mathrm{g}$ per day during the initial two month treatment period. $^{21}$

These findings are consistent with the dose-response relation in adolescents and adults in which $80-90 \%$ of the maximum obtainable effect is achieved at doses of between 100 and $250 \mu \mathrm{g}$ per day. ${ }^{1}$ They are also consistent with the large placebo controlled study of budesonide in children, which showed a plateau in dose-response between 200 and $400 \mu \mathrm{g}$ per day for all clinical outcome measures. ${ }^{27}$ This dose of budesonide is equivalent to $100-200 \mu \mathrm{g}$ per day of fluticasone when the potency difference is considered. ${ }^{28}$

\section{Adrenal suppression}

The dose-response relation of the systemic effects appeared to differ from that for efficacy with no difference in 24 hour urinary cortisol between placebo and fluticasone at doses of 100 and $200 \mu \mathrm{g}$ per day in the larger study, ${ }^{15}$ although the two smaller studies did report evidence of a reduction in urinary cortisol at these doses. ${ }^{162}$ In the study of Verona and colleagues, ${ }^{20}$ fluticasone at $400 \mu \mathrm{g}$ per day caused adrenal suppression in a small but clinically significant proportion of children compared with the $200 \mu \mathrm{g}$ per day dose. ${ }^{20}$ This finding is complemented by the study of Kannisto and colleagues $^{23}$ in which $20 \%$ of the asthmatic children had an abnormal response to ACTH stimulation with fluticasone at $500 \mu \mathrm{g}$ per day. In contrast, in the study of de Benedictis and colleagues, ${ }^{29}$ there was no reduction in overnight urinary cortisol at a dose of fluticasone of $400 \mu \mathrm{g}$ per day.

Taken together, these findings suggest that fluticasone is unlikely to cause adrenal suppression at $200 \mu \mathrm{g}$ per day with significant adrenal suppression occurring in some children at 400 to $500 \mu \mathrm{g}$ per day. This is generally consistent with the recent case reports ${ }^{2-9}$ of adrenal insufficiency in children taking $\geqslant 500 \mu \mathrm{g}$ per day, but more commonly $\geqslant 1000 \mu \mathrm{g}$ per day of fluticasone, suggesting that in susceptible individuals the systemic effects at these dose levels may be of clinical significance.

As a result, available evidence indicates that the doseresponse for adrenal suppression with inhaled fluticasone is different for children than for adults. In contrast to our findings, in adults the use of fluticasone in doses up to $500 \mu \mathrm{g}$ per day rarely causes adrenal suppression. ${ }^{30-34}$ In recognition of this difference, the British Thoracic Society recommends a maximum dose of fluticasone of 400 and 1000 $\mu \mathrm{g}$ per day for children and adults respectively. ${ }^{35}$

Table 5 Summary of studies included in systematic review of trials of the adrenal effects of fluticasone propionate in children with asthma

\begin{tabular}{|c|c|c|c|c|c|c|c|c|c|}
\hline \multirow[b]{2}{*}{ Study } & \multirow[b]{2}{*}{$\begin{array}{l}\text { No. of } \\
\text { patients }\end{array}$} & \multirow[b]{2}{*}{$\begin{array}{l}\text { Duration } \\
\text { of study } \\
\text { (weeks) }\end{array}$} & \multirow[b]{2}{*}{$\begin{array}{l}\text { Dose of } \\
\text { fluticasone }(\mu \mathrm{g} / \\
\text { day) }\end{array}$} & \multirow[b]{2}{*}{ Device } & \multirow[b]{2}{*}{$\begin{array}{l}\text { Range (mean) } \\
\text { of } \mathrm{FEV}_{1} \text { as } \% \\
\text { of predicted }\end{array}$} & \multirow[b]{2}{*}{$\begin{array}{l}\text { Age } \\
\text { (mean) }\end{array}$} & \multicolumn{3}{|c|}{ Outcome measures } \\
\hline & & & & & & & $\begin{array}{l}\text { Urinary } \\
\text { cortisol }\end{array}$ & $\begin{array}{l}\text { Urinary } \\
\text { cortisol } \\
\text { metabolites }\end{array}$ & LDST \\
\hline \multicolumn{10}{|c|}{ Placebo controlled } \\
\hline 15 & 437 & 12 & $\begin{array}{l}\text { Placebo } \\
100 \\
200\end{array}$ & $\begin{array}{l}\text { Diskhaler } \\
\text { Diskus }\end{array}$ & $50-85(73)$ & $6-11$ & $\sqrt{ }(24 \mathrm{~h})$ & $x$ & $x$ \\
\hline 22 & 52 & 52 & $\begin{array}{l}\text { Placebo } \\
100\end{array}$ & Diskhaler & PEF 86 & $4-10(8)$ & $\sqrt{ }(24 \mathrm{~h})$ & $x$ & $x$ \\
\hline 16 & 34 & 12 & $\begin{array}{l}\text { Placebo } \\
200\end{array}$ & Diskhaler & $>75(90)$ & $8-14(10.5)$ & $\sqrt{\text { (morning) }}$ & $x$ & $x$ \\
\hline 23 & 45 & 26 & $\begin{array}{l}\text { Placebo } \\
500\end{array}$ & Diskus & - & $5-15(9.5)$ & $x$ & $x$ & d \\
\hline \multicolumn{10}{|c|}{ Non-placebo controlled } \\
\hline 20 & 528 & 52 & $\begin{array}{l}200 \\
400\end{array}$ & Diskhaler & PEF 103 & $4-11(8)$ & $\sqrt{\text { (overnight) }}$ & $x$ & $x$ \\
\hline
\end{tabular}


The case reports also highlight the need for better appreciation of the greater potency of fluticasone compared with budesonide and beclomethasone. ${ }^{28} \mathrm{~A}$ feature of some of the case reports ${ }^{4}{ }^{6}$ has been the change from beclomethasone or budesonide to fluticasone at a similar daily dose, which effectively has resulted in a twofold increase in the therapeutic dose of inhaled corticosteroid.

\section{Circumstances when higher doses may be warranted} Our findings do not exclude the possibility that there may be circumstances when higher doses of fluticasone may be required. Due to the individual variability in response, a proportion of patients will require higher doses to achieve the maximum effect, just as a proportion may require lower doses. There is preliminary evidence that high doses of fluticasone may be effective in the situation of acute exacerbations of asthma, ${ }^{36}{ }^{37}$ Another situation is the use of fluticasone in patients dependent on oral steroids. In the only study $^{38}$ investigating the oral steroid sparing effect of fluticasone in children, a dose of $1000 \mu \mathrm{g}$ per day enabled two thirds of the children to discontinue their oral steroids altogether over a six month period.

\section{Recommended use}

We recommend that in children with asthma, fluticasone is routinely prescribed within the 100 to $200 \mu \mathrm{g}$ per day dose range, with consideration of a therapeutic trial of $400 \mu \mathrm{g}$ per day in children with severe asthma not controlled on the lower dose. This approach should improve the risk:benefit ratio for the use of fluticasone in children.

\section{Authors' affiliations \\ M Masoli, R Beasley, Medical Research Institute of New Zealand, Wellington, New Zealand \\ M Weatherall, Wellington School of Medicine \& Health Sciences, Wellington, New Zealand \\ S Holt, P3 Research, Wellington, New Zealand}

Competing interests: The Medical Research Institute of New Zealand, the Wellington School of Medicine and Health Sciences, and P3 Research have all received research grants from Astra Draco, GlaxoSmithKline, and Novartis. Richard Beasley and Shaun Holt have received fees for consulting and speaking and reimbursement for attending symposia from Astra Draco, GlaxoSmithKline and Novartis. Matthew Masoli has received reimbursement for attending symposia from Astra Draco and Novartis.

\section{REFERENCES}

1 Holt S, Suder A, Weatherall M, et al. Dose-response relation of inhaled fluticasone propionate in adolescents and adults with asthma: meta-analysis. BMJ 2001;323:253-6.

2 Todd G, Dunlop K, McNaboe, et al. Growth and adrenal suppression in asthmatic children treated with high dose fluticasone propionate. Lancet 1996;348:27-9.

3 Taylor AV, Laoprasert N, Zimmerman D, et al. Adrenal suppression secondary to inhaled fluticasone propionate. Ann Allergy Asthma Immunol 1999;83:68-70.

4 Duplantier JE, Nelson RP Jr, Morelli AR, et al. Hypothalamic-pituitary-adrenal axis suppression associated with the use of inhaled fluticasone propionate. J Allergy Clin Immunol 1998;102:699-700.

5 Wong J, Zacharin M, Hocking N, et al. Growth and adrenal suppression in asthmatic children on moderate to high doses of fluticasone propionate. J Paediatr Child Health 2002;38:59-62.

6 Todd GRG, Acerini CL, Buck JJ, et al. Acute adrenal crisis in asthmatics treated with high-dose fluticasone propionate. Eur Respir J 2002;19:1207-9.

7 Drake AJ, Howells RJ, Shield JPH, et al. Symptomatic adrenal insufficiency presenting with hypoglycaemia in children with asthma receiving high dose inhaled fluticasone propionate. BMJ 2002;324:1081-2.

8 Zahra S, Acerini C, Ross-Russell R, et al. National survey (UK) of adrenal crisis due to inhaled corticosteroids. Arch Dis Child 2002;86(suppl 1):G108.

9 Patel L, Wales JK, Kibirige MS, et al. Symptomatic adrenal insufficiency during inhaled corticosteroid treatment. Arch Dis Child 2001;85:330-3.
10 Brown PH, Blundell G, Greening AP, Crompton GK. Screening for hypothalamic-pituitary-adrenal axis suppression in asthmatics taking high dose inhaled corticosteroids. Respir Med 1991;85:511-16.

11 Lipworth BJ, Seckl JR. Measures for detecting systemic bioactivity with inhaled and intranasal corticosteroids. Thorax 1997;52:476-82.

12 Ellul-Micallef R. Hypothalamic-pituitary-adrenal function in asthma. Bronchial asthma. In: Weiss E, ed. Mechanisms and therapeutics, 3rd edn. Boston: Myron Stein, 1993.

13 Sutton AJ, Abrams KR, Jones DR, et al. Methods for meta-analysis in medical research. Chichester: Wiley, 2000.

14 LaForce CF, Pearlman DS, Ruff ME, et al. Efficacy and safety of dry powder fluticasone propionate in children with persistent asthma. Ann Allergy Asthma Immunol 2000;85:407-15.

15 Peden D, Berger W, Noonan $M$, et al. Inhaled fluticasone propionate delivered by means of two different multidose powder inhalers is effective and safe in a large paediatric population with persistent asthma. J Allergy Clin Immunol 1998;102:32-8.

16 Hoekstra MO, Grol M, Bouman K, et al. Fluticasone propionate in children with moderate asthma. Am J Respir Crit Care Med 1996;154:1039-44.

17 Katz Y, Lebas FX, Medley HV, et al. Fluticasone propionate $50 \mu \mathrm{g}$ BID versus $100 \mu \mathrm{g} \mathrm{BID}$ in the treatment of children with persistent asthma. Clin Ther 1998;20:424-37

18 MacKenzie CA, Weinberg EG, Tabachnik E, et al. A placebo controlled trial of fluticasone propionate in asthmatic children. Eur J Pediatr 1993; 152:856-60.

19 Hofstra W, Neijens H, Duiverman E, et al. Dose-responses over time to inhaled fluticasone propionate treatment of exercise and methacholine induced bronchoconstriction in children with asthma. Paediatr Pulmonol 2000;29:415-23.

20 Verona E, Petrov D, Cserhati E, et al. Fluticasone propionate in asthma: a long term dose comparison study. Arch Dis Child 2003;88:503-9.

21 Visser M, Postma $D$, Arends $L$, et al. One year treatment with different dosing schedules of fluticasone propionate in childhood asthma. Am J Respir Crit Care Med 2001; 164:2073-7.

22 Price J, Russell G, Hindmarsh P, et al. Growth during one year of treatment with fluticasone propionate or sodium cromoglycate in children with asthma. Paediatr Pulmonol 1997:24:178-86.

23 Kannisto S, Korppi M, Remes K, et al. Adrenal suppression, evaluated by a low dose adrenocorticotropin test and growth in asthmatic children treated with inhaled steroids. J Clin Endocrinol Metab 2000;85:652-7.

24 Brown PH, Blundell G, Greening AP, et al. Hypothalamo-pituitary-adrenal axis suppression in asthmatics inhaling high dose corticosteroids. Respir Med 1991;85:501-10.

25 Burch W. Urine free cortisol determination. A useful tool in the management of chronic hypoadrenal states. JAMA 1982;247:2002-4.

26 Bisgaard H, Damkjaer Nielsen M, Andersen B, et al. Adrenal function in children with bronchial asthma treated with beclomethasone dipropionate or budesonide. J Allergy Clin Immunol 1988;81:1088-95.

27 Shapiro G, Bronsky E, LaForce C, et al. Dose-related efficacy of budesonide administered via a dry powder inhaler in the treatment of children with moderate to severe persistent asthma. J Paediatr 1998;132:976-82.

28 Adams N, Bestall JM, Jones PW. Fluticasone versus beclomethasone or budesonide for chronic asthma (Cochrane review). In: Cochrane Library, Issue 1, 2002.

29 de Benedictis FM, Teper A, Green RJ, et al. Effects of two inhaled corticosteroids on growth: results of a randomized controlled trial. Arch Paediatr Adolesc Med 2001;155:1248-54.

30 Pearlman DS, Noonan MJ, Tashkin DP, et al. Comparative efficacy and safety of twice daily fluticasone propionate powder versus placebo in the treatment of moderate asthma. Ann Allergy Asthma Immunol 1997;78:356-62.

31 Li JT, Ford LB, Chervinsky $P$, et al. Fluticasone propionate powder and lack of clinical significant effects on hypothalamic-pituitary-adrenal axis and bone mineral density over 2 years in adults with mild asthma. J Allergy Clin Immunol 1999;103:1062-8.

32 Wasserman SI, Gross GN, Schoenwetter WF, et al. A 12-week dose-ranging study of fluticasone propionate powder in the treatment of asthma. J Asthma 1996;33:265-74.

33 Sorkness CA, LaForce C, Storms W, et al. Effects of the inhaled corticosteroids fluticasone propionate, triamcinolone acetonide, and flunisolide and oral prednisone on the hypothalamic-pituitary-adrenal axis in adult patients with asthma. Clin Ther 1999;21:353-67.

34 Shapiro G, Lumry W, Wolfe J, et al. Combined salmeterol $50 \mu \mathrm{g}$ and fluticasone propionate $250 \mu \mathrm{g}$ in the discus device for the treatment of asthma. Am J Respir Crit Care Med 2000;161:527-34.

35 Anon. British Guideline on the Management of Asthma. Thorax 2003;58(suppl 1):1-83.

36 Bingham A, Manira AL, Lee BW, et al. A comparison of the effect of nebulised fluticasone propionate $1 \mathrm{mg}$ twice daily with oral prednisone in children 4-16 years with an acute exacerbation of asthma. Am J Respir Crit Care Med 1998;157(3):A404

37 Manira Al, Price J, Lenney W, et al. Efficacy of nebulised fluticasone propionate compared with oral prednisolone in children with an acute exacerbation of asthma. Respir Med 2000;94:1206-14.

38 Shekh S, Goldsmith U, Eid N. Oral steroid sparing effect of inhaled fluticasone propionate in children with steroid-dependent asthma. Paediatr Child Health 2000;5:156-60. 